\title{
'Dreaming in colour': disabled higher education students' perspectives on improving design practices that would enable them to benefit from their use of technologies
}

\author{
Jane Seale ${ }^{1}$ (D) Chetz Colwell $^{1} \cdot$ Tim Coughlan $^{1} \cdot$ Tali Heiman $^{2}$ (D) \\ Dana Kaspi-Tsahor ${ }^{2}$. Dorit Olenik-Shemesh ${ }^{2}$
}

Received: 20 December 2019 / Accepted: 8 September 2020 / Published online: 16 September 2020

(C) The Author(s) 2020

\begin{abstract}
The focus of this paper is the design of technology products and services for disabled students in higher education. It analyses the perspectives of disabled students studying in the US, the UK, Germany, Israel and Canada, regarding their experiences of using technologies to support their learning. The students shared how the functionality of the technologies supported them to study and enabled them to achieve their academic potential. Despite these positive outcomes, the students also reported difficulties associated with: i) the design of the technologies, ii) a lack of technology know-how and iii) a lack of social capital. When identifying potential solutions to these difficulties the disabled students imagined both preferable and possible futures where faculty, higher education institutions, researchers and technology companies are challenged to push the boundaries of their current design practices.
\end{abstract}

Keywords Disability $\cdot$ Higher education $\cdot$ Technology $\cdot$ Design $\cdot$ Accessibility

\section{Introduction}

The focus of this paper is the design of technologies for disabled students attending higher education. For the purpose of this paper we define disability broadly to include physical, sensory, mobility and cognitive disabilities. In particular, we are interested in those disabled students who attend colleges, technical schools (that offer certificate programs) and universities. We define technologies broadly to include online learning

Jane Seale

jane.seale@open.ac.uk

1 The Open University, Milton Keynes, UK

2 The Open University of Israel, Ra'anana, Israel 
(both distance and blended learning); assistive technologies (AT) such as screenreaders and alternative keyboards; general use technologies such as tablets and mobile phones; administrative applications such as registration systems; social and networking applications such as Facebook and Twitter as well as specific application technologies such as statistical packages. The particular problem the paper will address is the disadvantage that disabled students in higher education experience, the role technology plays in mediating (for better or worse) this disadvantage and the implications this has for design practice- where design is understood as the design of both products (mainstream and assistive technologies) and services (the support disabled students receive to use technologies) (McCauley 2019). ${ }^{1}$

Over $11 \%$ of students enrolled in 2-year and 4-year colleges in Canada and the United States have a disability (Fichten et al. 2018; Snyder et al. 2016). Similar percentages have been reported in other countries. For example, a recent investigation noted that $12 \%$ of undergraduates had a disability in the United Kingdom (Advance 2018). These figures have increased from 6\% in 1996 in the US and 1.18\% in 1994 in the UK (Seale 2014). There are variations in these figures however, particularly for those some institutions that have traditionally attracted more disabled students. For example, for the Open University in the UK, figures for 2017/18 suggest that $21 \%$ of its student cohort have a declared a disability (HESA 2019). At the Open University of Israel, almost $9 \%$ of students asked for learning accommodation due to their disabilities (The Open University Report 2018). There is evidence to show that disabled students in higher education are less likely than nondisabled students to stay enrolled, earn a higher degree or secure employment (Mamiseishvili and Koch 2012). Some studies have found that disabled students in higher education take additional time to graduate (Arim 2017; Knight et al. 2018). Whilst other studies show that disabled students are more likely to drop out than their non-disabled peers (Rosenbaum 2018) and less likely to graduate (Advance 2018). With regard to employment, studies have shown that disabled graduates are also disadvantaged. For example, Jorgensen et al. (2015) found that of those higher education graduates with disabilities employed or looking for just $70 \%$ were employed a year after graduation, a figure somewhat lower than the employment rate of students without disabilities. The same is true in the United Kingdom (Advance 2018). Studies in Britain, Canada and America also reveal that disabled students who enrol, but do not complete a higher education program, are less likely to be employed and receive a lower salary than a non-disabled graduate (Advance 2018; Jorgensen et al. 2015; Ma et al. 2016).

Research in the field, has consistently identified and described a range of benefits that technology can afford disabled students in Higher Education which have the potential to mitigate in some way the disadvantages that they experience. For example, for visually impaired students, technologies such as laptops and e-books are highlighted as they enable the student to receive course material that is traditionally printed on paper in a digital format, this can then be accessed by technologies such as screenreaders (Bishop and Rhind 2011). Students with learning disabilities (e.g. dyslexia) report benefitting from technologies that can assist in their reading, writing and organisation of information such as spell-checkers and mind-mapping software

\footnotetext{
${ }^{1}$ McCauley, C (2019) Design community - we need to talk about disabled people

https://swimminginstormyweather.wordpress.com/2019/06/03/design-community-we-need-to-talk-aboutdisabled-people/
} 
(Roberts and Stodden 2005; Price 2006). Disabled students also appreciate the flexibility that technologies can offer, through the provision of distance learning opportunities (Hammer et al. 2007). When lecturers make materials available on a course web site or a course management system or online education platform this allows students to interact with learning materials outside of the lecture room this can be particularly beneficial for those students with mobility impairments and mental illness as they can access the course from home and still feel part of the learning community (Fichten et al. 2020). In the United Kingdom, Disabled Students' Allowances (UCAS 2018) are available to eligible students. The Allowance can fund both technological (mainstream and specialist technologies) and human support. What makes this particularly valuable is that data show that such allowances have a favourable impact on graduation; $73.9 \%$ of disabled students who qualified and received the Disabled Students Allowance achieved first-class or upper second-class honours compared to $72.5 \%$ of those who did not receive the Allowance (Advance 2018).

Despite these potential benefits, there is a significant amount of evidence to indicate that technology can also have a negative influence on the study experiences of disabled students. A commonly reported technology-related barrier to positive experiences is the technical inaccessibility of learning platforms (Brandt 2011; Policy Connect 2018), online courses including MOOCs (Roberts et al. 2011; Iniesto et al. 2016; SanchezGordon and Luján-Mora 2018), websites (Kimmons 2017; Seale 2014; Alahmadi and Drew 2017), text-books (McNaught et al. 2018; Fichten et al. 2020), lecture material such as pdfs and PowerPoint slides (Fichten et al. 2009) and social media (Asuncion et al. 2012). Other reported barriers reported include: difficulties obtaining technologies (Reed et al. 2006); unanticipated time demands required learning how to use assistive technologies (Hanafin et al. 2007); technology use being contested or valued differently by lecturers (Claiborne et al. 2011); being recommended technology based on disability labels rather than need (Stodden and Conway 2003) and lack of availability of adapted computers in campus-based computer laboratories (Fichten et al. (2010a, 2010b). The phenomenon of technology both mitigating and exacerbating the disadvantage that disabled students experience has been labelled a 'double-edged sword' (Seale 2006:p25). It was first identified in the late 1990's and has continued into the twenty-first Century (Fichten et al. 2020).

\section{Literature review}

Research in the field has attempted to resolve the conundrum of the 'double-edge sword' by seeking to understand in more detail the difficult or negative experiences of disabled students in order to identify potential solutions that would lessen or remove these experiences. In this section we will provide an overview of this research and through this overview identify gaps in knowledge that the research reported in this paper will attempt to address.

\subsection{Disabled students' experiences of technology}

Studies exploring disabled students' experiences of technology fall into four categories: i) identifying patterns of technology access and use ii) identifying disabled students' 
perceptions of technology iii) identifying outcomes of technology use and iv) identifying factors that influence technology use.

\subsubsection{Patterns of technology use}

Studies exploring patterns of technology access and use reveal that disabled students combine both assistive and mainstream technologies to support their studies. For example, with regard to assistive technology, Heiman and Olenik-Shemesh (2012) and Heiman et al. (2016) examined the accessibility and the contribution of assistive technology to both disabled and non-disabled students in higher education in Israel. Unsurprisingly, they found that disabled students were more familiar with assistive technology than non-disabled students. More specifically, they found that students with learning disabilities frequently utilized assistive technology as an additional study tool during their studies. 55\% of them used Text-to-Speech, $45 \%$ used spell checkers, $41 \%$ used audiobooks. In a study of 131 French and 1202 English speaking disabled students studying at English Language universities and junior community colleges in Canada, Fichten et al. (2010a) used their POSITIVES questionnaire to measure how well students' ICT needs were met at home and at university or college. The most common software and hardware that both English and French speaking students used were those that helped with writing such as spelling and grammar checkers, prediction software, mind-mapping software and adapted keyboards. While some students appear to really benefit from using assistive technologies, a small number of studies have revealed that some disabled students choose to abandon their assistive technologies (e.g. Goodman et al. 2002; Roberts and Stodden 2005) Reasons given for abandonment include lack of training on how to use the assistive technology, not having the time to learn a new piece of technology and the assistive technology not being as functional or helpful as the student would like (we will return to these issues in the later section on factors that influence technology use).

With regard to mainstream technologies studies have revealed that many disabled students (although not all) like using course management systems to print off notes before lectures (Gerrard 2007); find using email and instant messaging an effective way of communicating with peers and tutors (Eden and Heiman 2011); use mobile phones as a memory aid, spell-checker and calculator (Fichten et al. 2019) and use social media both for study and non-study purposes (Asuncion et al. 2012). There is also evidence to suggest that disabled students view many mainstream technologies as 'assistive' and don't necessarily find it helpful to distinguish between mainstream and specialised assistive technology (Seale et al. 2008). Fichten et al. (2020) argue that disabled students are blurring the divisions between mainstream and assistive technologies and that this gives them access to a vast arrange of technologies from which to choose.

\subsubsection{Disabled students' perceptions of technology}

Studies have sought to ascertain disabled students' perceptions regarding the benefits of using technology. Some studies reveal largely positive student evaluations of technology. For example, Graves et al. (2011) conducted semi-structured interviews of 11 students with specific learning disabilities to investigate whether asynchronous online access to course recordings was beneficial. The students felt that technology enhanced 
the course concepts and skills, increased organization of course material, increased convenience, and improved achievement. More interestingly, they felt that accessing asynchronous online information provided a 'disability coping mechanism'; it helped them self-accommodate the impact of their disability.

It is more common however, for studies to show that students neither accept nor reject technologies outright; they can see both positive and negative aspects to technology use indicating that they have a more complex relationship with technologies than some literature in the field suggests. For example, Unterfrauner and WeiermairMärki (2008) surveyed and interviewed 87 disabled Austrian students. Using a method informed by the critical incident technique, participants are asked to identify specific incidents which they had experienced personally and which had made a significant positive or negative contribution. Deaf and hearing impaired students in the study reported both positive and negative aspects of technology use. On the positive side, students with hearing impairments said that the use of technology improved their situation as students considerably. Online registration for courses or assessments and online discussion boards to exchange ideas with other students particularly helped those having problems in communicating with others. Information that they would have previously had to gather personally at university offices or with the help of another person via telephone, could now be easily retrieved through the Internet or via email, thus improving the autonomy of the person concerned. On the negative side deaf students complained that videos were rarely captioned. Blind students reported problems accessing information in the VLE and some students with visual impairments reported that the process of getting alternative formats very much depended on the good will of the lecturers.

Lewthwaite (2011) explored the experiences of disabled university students in using social networking sites such as Facebook. Lewthwaite was interested in exploring, through internet enabled interviews, how dis/ability and difference were ascribed and negotiated within social networking sites. In her thesis she presented case studies of 18 disabled students from three universities. The case studies revealed that students' experiences were complex and diverse. For some students, using Facebook represented an opportunity to create non-disabled identities, build social capital and mitigate impairment. Other student experiences were less enabling. As a result Lewthwaite observed that for some students, 'the network' supported 'normal' status, for others, the 'network' had to be resisted as a form of social domination.

\subsubsection{Outcomes of technology use}

A small body of research has sought to quantify the impact that technology has on the academic success of disabled students whilst in Higher Education, their social wellbeing and their attainment post HE. For example, Hecker et al. (2002) studied how 20 higher education students with attention disorders used assistive reading software, Kurzweil, to see if it would affect reading performance. These students used the software for most of a semester to read assignments for an English class and in testing sessions in which comparisons were made between normal, unassisted reading, and reading assisted by the software. Results revealed that students using the software could read faster, with less stress and fatigue. There is however, no commonly accepted definition of academic success as yet and few, if any, validated instruments for 
measuring academic success. Other possible conceptualisations of academic success could include performance in academic assessments, retention of lecture information; quality of note-taking and could depend on the kind of technology being used by a disabled student and the context or purpose of its use. Other researchers are starting to look at psychosocial outcomes related to well-being. For example, Heiman and OlenikShemesh (2012) examined the impact of using technology on the perceived well-being (as measured by a global-hope scale) of students with learning disabilities (e.g. dyslexia). The found a positive correlation between the use of assistive technologies and web-based courses and well-being. In an additional study focusing this time on students with visual impairment, Kaspi-Tsahor et al. (2011) found that use of assistive technologies contributed to both students' academic and socio-emotional satisfaction.

Bouck et al. (2012) used data from the National Longitudinal Transition Study-2 (NLTS-2) collected in the mid 2000's to explore the relationship between receipt of assistive technologies in school and post school outcomes. The NLTS-2 involved five phases of data collection from disabled students, parents, teachers and other school personnel regarding the in-school and post-school experiences of a national sample of disabled students, aged between 13 and 16 in 2000. The post-hoc analysis of this data by Bouck et al. revealed a complex relationship between receipt of assistive technologies and outcomes. Few students in this study reported receiving assistive technologies in high school (7.85) and fewer still after high school (1.1\%). Students with highincidence disabilities (e.g. learning disability, emotional and behavioural disorders) who received assistive technology in school had higher graduation rates, had higher rates of paid jobs, were less likely to be earning less than the minimum wage, and were more likely to have attended a higher education institution. Yet no student who received assistive technology in school was living independently, and fewer were working full-time.

\subsubsection{Factors that influence technology use}

In order to understand why technology is not having a solely positive influence on disabled students in higher education it is important to understand the factors that influence their use of technology. Studies exploring this influence have identified three major factors: whether disabled students know how to use the technology; the support they have to use (and learn to use) the technology and the time available to them to use (and learn to use) the technology.

Studies that have examined disabled students' knowledge of technologies have focused on both confidence levels and skill levels. In a study of 32 dyslexic and nondyslexic students, Woodfine et al. (2008), found evidence of a lack of confidence in some dyslexic students in their study of the use of the Virtual Learning Environment, WebCT. They noted that synchronous communication was such a new challenge that some dyslexic students just avoided it and did not even attempt to participate; or they felt alienated when they did participate. This could result in dyslexic students antagonising their peers and tutors which in turn had the potential to reduce the likelihood of them receiving help and support. Studies conducted by Seale and colleagues (Seale et al. 2010, Seale 2013, Seale et al. 2015) however found quite strong evidence that some disabled students have high levels of confidence in their ability to use technology to support their studies. In a study of 32 students with a range 
of disabilities, Seale et al. (2010) and Seale (2013) found that they were highly confident in using technologies and that their confidence levels were linked to how familiar or comfortable they felt with the technology. In a survey of 175 disabled students, Seale et al. (2015) found that the majority rated their confidence level highly (average of 7.4 out of 10 on confidence scale). In explaining their levels of confidence, the students considered that the nature and value of technologies and having access to high quality training influenced their confidence levels.

The studies by Seale and colleagues also revealed that disabled students were highly skilled in their use of technologies. Seale et al. (2010) referred to this ability as 'digital agility'. The evidence they presented to support their claim included the fact that the majority of students used instant messaging; participated in discussion forums; used social networking sites such as Facebook and uploaded videos or photos onto the Internet. All the participants used search engines such as Google, accessed online learning materials; used word-processors and spreadsheets and contacted tutors using email. Furthermore, all the students customised their computer; particularly toolbars, menu items and the font size on screen to suit their particular learning preferences. The most common strategies adopted by students to enhance their learning efficiency tended to be related to accessing computers/ information and coping with written work. These strategies therefore involved the use of both specialist assistive technologies (e.g. Inspiration or Dragon Dictate) as well as more generic technologies (e.g. mobile phone or Google). These strategies were often quite inventive, for example using three different assistive technologies together. In addition, many students demonstrated a sophisticated awareness of the pros and cons of using a wide range of technologies and were able to talk about which particular properties influenced their decisions to use technology. The two most frequently mentioned properties were: the efficiency offered in terms of time management (e.g. organising essays, finding references) and whether or not the technology supported learning or socialising (Seale 2013). Seale et al. (2015) referred to the skill levels of disabled students as 'digital cultural capital'. Examples of this capital, included: the majority of survey respondents had: experience of search engines; used an electronic library or portal; used online learning materials they had found for themselves; used presentation software such as PowerPoint; contacted tutors or peers using email; accessed course materials via and online learning environment. In addition, the majority of disabled students in the survey were experienced in using technologies for self-management with $83.2 \%$ using a computing device to plan assignments and $69.9 \%$ using a computing device to record lectures. 22 interview respondents identified 15 strategies for employing AT to support their learning, with the most common being recording and transcribing, audible proof-reading and assistance with reading text on screen. They were also highly knowledgeable about the affordances and constraints of technologies.

The literature identifies three sources of support that students either value or find problematic: support form faculty (e.g. lecturers/tutors); support from student services (e.g. assistive technologists, disabled students officers) and support from peers (e.g. other disabled students, or students on same course, in same university). When faculty support disabled students to use their technology or ensure that digital course material is accessible research reveals that students value this highly (Seale 2006). For example, Blankfield and Martin (2002) evaluated a six week access to higher education course, with twelve disabled students and found that the publishing of lecture notes or 
PowerPoint presentations onto the computer network in advance of lectures was perceived to be particularly helpful to all of the participants, including those without learning difficulties. Having these documents before the lecture meant that the students could make more meaningful notes, which they considered aided their learning and understanding. However, the majority of research that evaluates disabled students experiences of faculty support, report dissatisfaction with poor practices such as a lack of awareness of the value of technologies or actively preventing disabled students from using technologies. These poor practices do not appear to have lessened over time. For example, in 1998, Roessler and Kirk conducted a telephone interview with 40 recent disabled college graduates regarding the type and quality of technology services they received in college. Although students were satisfied with the auxiliary classroom aids and technology information they had received, the majority of the participants rated their academic advisors' knowledge of technology as being inadequate to meet their needs. Over twenty years later and Fichten et al., (in press) report that professors often dislike the presence of students' personal devices in class and, in some cases, forbid their presence. It is perhaps not surprising then, that if students have a choice of who to call on for support with technology use, faculty are not the first choice. For example, in the survey by Seale et al. (2015), when asked which sources of support they accessed at school or college if they needed help using AT, the majority of disabled students indicated that their most helpful source of support was learning support staff, followed by privately funded support workers and friends from school or college. When asked which sources of support they accessed at school or college if they needed help using general technologies, survey respondents indicated that their most helpful source of support was friends, followed by learning support staff and teachers/lecturers.

Studies reporting the impact of student support services on disabled students' use of technologies reveal a mixture of satisfaction and dissatisfaction. Roberts et al. (2011) used the Disabled Students and Online Learning (SDOL) tool to survey 2366 disabled students in five top ranking US colleges in the US. This survey records demographic information, documented disabilities and online experiences. Over $45 \%$ of students indicated that they were very satisfied or satisfied with their institutions ability to accommodate their disabilities. Over $6 \%$ indicated some level of dissatisfaction. Fichten et al. (2010a, 2010b) conducted a survey using the POSITIVES scale of 1354 disabled college and university students studying in Canada. The survey focused on how well their ICT needs were being met. The results were largely positive, with students reporting that expertise in adaptive ICTs was readily available on campus. There were concerns however, regarding the availability of adapted computers in the school's specialized computer laboratories as well as with institutional computer technology loan programs. Davies (2007) conducted 5 focus groups of disabled student from across Wales in the UK. Issues identified were: assistive software not kept updated; appropriate hardware not always available; software not networked; location of assistive technologies and lack of appropriate support and training. Ari and Inan (2010) surveyed 22 disabled Turkish undergraduate and post graduate students using an adapted version of the Technology for Disabled students Survey (TSDS). This survey looks at demographic characteristics, technology status, student perception and disposition towards technology. Results revealed limited school facilities for disabled students, accompanied by a severe lack of necessary staff orientation or training in regard to teaching disabled students. Additional facilities, when available, were ill- 
equipped to address student instructional needs. More critically, the schools had failed to provide equal opportunities to those students with special needs while taking course exams. Despite this, Ari and Inan (2010) consider it promising that almost one-half of the students surveyed had the opportunity to use a computer reserved for 'special needs students'.

Research studies have found that disabled students both value and benefit from support from their peers. Peer support might come from other disabled students. For example, Roer-Strier (2002) reports on efforts at Hebrew University to support the technology needs of students with learning disabilities. On the basis of student needs identified through a first-year evaluation, the school opened a special computer course for students with learning disabilities, aimed at utilizing specialist computer technology. The course earned much positive commentary at the end of year feedback session. Students reported that the course improved their personal abilities and gave them a sense of partnership with other students with learning disabilities, which reduced their feelings of social isolation. Ari and Inan (2010) found that when disabled students received support and encouragement from their peers, or witnessed the utilization of technology by others, their beliefs about what they could do with technology increased. They concluded that informing disabled students about computer technologies and/or allowing them to observe computer use by their peers might lead to an increase in their belief in their own ability to utilize technology.

Peer support might also emanate from non-disabled students, Seale (2013) reports that the disabled students in their study appeared to prefer to seek support for their technology use either from students who were studying the same course or living in the same halls of residence (i.e. neighbours). The data from the survey conducted by Seale et al. (2015) however, reveals a more complex picture in relation to how the disabled students choose to interact with their peers. Firstly, survey respondents rated support to use generic technologies as more helpful when it came from friends compared to more formal support services. Conversely the help from friends with specialist technologies was rated less helpful than more formal support services. Thirdly, respondents did not rate the support from other disabled students as highly as other sources.

In a study of dyslexic students' use of voice recognition software (VRS), time was revealed as a significant factor for eight of the twelve participants (Roberts and Stodden 2005). Six of these participants stated they did not have enough time to continue to use the software while keeping up with their coursework. One student indicated that she used the software but did not have time to learn all aspects of the program. Students also reported that the VRS was more time consuming to use than they originally thought it would be. Students thought they could sit down and use the software with little effort and minimal training, and that the software would perfectly recognize everything they said. The reality was the software required ongoing training that may be time consuming. Roberts and Stodden concluded that if the participants were trained on the software during a time when other demands on their time were minimal they may be more inclined to use the software and find it beneficial. Similar findings, for a broader range of disabilities were reported by Seale and colleagues (Seale et al. 2010; Seale 2013; Seale et al. 2015). For example in the 2015 study, the most common reason for abandoning technology was time. As one student said: "But time pressures are huge, definitely. I haven't got the time to get it wrong." 


\subsection{Proposed design solutions to the difficulties that disabled students experience}

When thinking about how to solve the problems that disabled people generally experiences with their technologies, a common response is to frame the potential solution as a design solution. We would argue the same is true with regard to trying to solve the problems that disabled students experience with their specialist and mainstream technologies (products) and the support they receive to use them (services). In higher education, the typical response is to attempt to change (re-design) practice. Seale (2014) identified that two commonly identified solutions to changing poor practice are training (professional development) and universal design. Both of these solutions need designing (planning) however and Seale argues that there is little consensus on what the best design is, or evidence that the design actually works.

\subsubsection{Training}

With regard to the training of faculty in order to improve their ability to increase the chances of technology providing positive learning experiences and outcomes for disabled students Seale (2014) identifies a range of factors that have been considered when designing training opportunities: What content to include: (e.g. technical accessibility issues; disability awareness, accessibility and equality related legislation and policy and design approaches such as Universal Design) 2. What pedagogical strategies to adopt: (e.g. embedded in broader training or a separate stand-alone module) 3. What mode of delivery: (e.g. online course, face-to face workshop, virtual reality, simulations).

Of the small number of training packages that have been designed and described in the literature (e.g. Izzo et al. 2008; Regadas and Ribeiro 2011; Quirk and Conway 2011; Papadopoulos et al. 2011) there is very little systematic and rigorous evaluation of the success of the training programs and the components designed within them. One example is the study by Thompson et al. (2007) who studied the impact of training on university web developers; where training (outreach) consisted of face-to-face training from external accessibility experts and follow-up email support. Web developers at 19 institutions were offered varying degrees of outreach support and the effect of this support was assessed by measuring the accessibility of the developers' websites both before and at different intervals after the training. Results revealed that overall; changes to web accessibility over time did not appear to be associated with the institutions' assigned outreach group. The websites of institutions that received moderate or extensive support showed positive change over time on just three out of fourteen accessibility checkpoints and negative change over time on three checkpoints.

Another, albeit less frequently considered aspect of training, is the need to embed accessibility and related issues into the undergraduate and postgraduate programmes of students who are studying to enter professions linked to the technology or services that disabled students use. Typically, commentators focus on computer science, web design or human computer interaction programmes (Lazaar et al. 2017; Heiman et al. 2020). Two particular factors that are taken into account when designing these programmes include: the potential to be integrated into the whole programme curriculum and how to give design students practical experience of designing for and with disabled people/ students. Based on his personal experiences of working with developers and engineers 
from a variety of companies in the USA, Rangin (2020) argues for an improvement in the education and training of designers. Rangin argues that higher education curricula of design and engineering departments provide limited education on accessibility and best practices, while some may exclude the topic completely. Design and engineering graduates therefore enter their respective fields without a clear understanding of the problems disabled students face.

\subsubsection{Universal design}

It is commonly argued, particularly in the US, that a viable solution to the poor practice of faculty and student support services is to encourage and train them to implement Universal Design (UD) principles and approaches. Universal Design Approaches in education are influenced in varying degrees by the work of Centre for Universal Design which conceived Universal Design as: 'the design of products and environments to be usable by all people to the greatest possible extent' (Centre for Universal Design, 1997). Seven principles were formulated to underpin this concept: Equitable Use, Flexibility in Use, Simple and Intuitive Design, Perceptible Information, Tolerance for Error, Low Physical Effort, and Size and Space Appropriate for Approach and Use. These principles, though tied to architecture and the physical environment, have at their core keeping as many users in mind as possible in the design and development process. Broadly speaking, universal design in educational contexts is an approach characterised by proactive design and inclusive instructional strategies that benefit a wide range of learners. There are however different approaches or branches to Universal Design in Education: Universal Design for Learning (CAST 2018), Universal Design for Instruction (Scott et al. 2003) and Universal Design in Higher Education (Burgstahler 2015). The latter two were developed specifically with higher education in mind.

The proponents of Universal Design for Instruction reworked the original seven design principles to fit a higher education context. The result was a list of nine principles for UDI (McGuire et al. 2003, p. 13). For example: 'Tolerance for error: Instruction anticipates variation in individual student learning pace and prerequisite skills'. Universal Design in Higher Education (UDHE) was adopted by a team of collaborators in several projects at the University of Washington (UW) UDHE builds upon a total of ten principles drawn from UD and UDL that allow for a wide range of possible applications in higher education, not only in teaching and learning, but also in other functional areas such as outdoor spaces, administrative websites and services (Burgstahler 2015; Burgstahler et al. 2020). For all specific applications, the ultimate goal of these proactive practices is access for everyone. The UDHE Framework makes clear that applying UD and UDL principles campus-wide does not eradicate the need for accommodations; it minimizes their necessity and thus reduces the need for disabled students to make special requests for them.

In a review of research and practice literature (Seale 2014, 2017) noted that a large amount of space was given to advocating the merits of UD and providing descriptions of UD informed practices. Seale however argued that the authors of this literature were rather too uncritical and should be demanding more concrete evidence that adopting this design practice actually produces the intended benefits for disabled students. One rare example, is an evaluation of the DO-IT programme designed using UDHE principles by Sheryl Burgstahler and others at the University of Washington (DO-IT. 
2016). In an external evaluation of DO-IT, SRI International found that the most important things that participants gained from the program are a sense of belonging (both academic and social integration), involvement (in academic and social life), a sense of purpose (through internships, workshops, networking and mentoring), and self-determination skills (development and practice).

In addition to arguing for the adoption of UD; proponents of UD also argue that faculty need to be trained how to apply UD in practice. However, there are few studies that have sought to rigorously evaluate the effectiveness of UD training (Seale 2014:Seale 2017). One rare example is that reported by Baldiris Navarro et al. (2016) who present an evaluation of a professional development program in relation to developing teachers' competences towards designing inclusive learning experiences. The program was based on UDL principles and was aligned with the Competence Framework for Inclusive Teachers (CFIT), and used the ADDIE (Analysis, Design, Development, Implementation, and Evaluation) Educational model. The authors found that the participants "demonstrated a considerable amount of growth between pre-test and post-test when designing an inclusive lesson plan" and the participants' scores to the assessment activity of the teacher PDP were considerably high and within the excellent performance level" (p25).

The studies reviewed in this section provide an insight, from a range of different countries over a large period of time, into disabled students' experiences of using technologies. Whilst potential solutions have been identified, they have not been identified or discussed by disabled students themselves. Instead they have been identified by stakeholders such as academic researchers with an interest in accessibility design (e.g. Papadopoulos et al. 2011; Lazaar et al. 2017) and service providers (e.g. Burgstahler 2015; Thompson et al. 2007; Rangin, 2020). The research reported in this paper attempts to address this gap in knowledge by asking disabled higher education students to share both the difficulties they experience with regard to using technology to support their learning and the potential design solutions that might solve or lessen these difficulties.

The authors of this paper are partners in a Leverhulme Trust funded International Network called Ed-ICT. Partners from US (Seattle), Canada (Montreal), UK (Milton Keynes), Germany (Hagen) and Israel (Tel Aviv) have held five symposia over the past three years in order to seek ways in which research can inform practice (and vice versa) in the field so that the disadvantage that disabled learners experience can be reduced or better still eliminated. A central premise of the Ed-ICT International Network was that the community needs to listen to the voices of all relevant stakeholders. Therefore for each symposium a range of stakeholders including disabled students, faculty, researchers, ICT companies and AT/access service providers were invited to participate and contribute. Each symposium included a panel session in which disabled students were invited to share their experiences of using technologies and identify potential solutions. In this paper we will report the outcomes of these sessions in order to address the following three research questions:

1. What are the technology related experiences of disabled students studying in US, UK, Germany, Israel and Canada?

2. What, if any, difficulties do disabled students studying in US, UK, Germany, Israel and Canada experience with regarding to technology access and use 
3. What potential solutions do disabled students studying in US, UK, Germany, Israel and Canada propose might address these difficulties?

\section{Methods}

The research took place between March 2017 and June 2019. During this period five symposia were held, each with a different theme, but all involving disabled students as key participants (See Table 1).

\subsection{Recruitment and participants}

Each symposium included a panel session in which disabled students were invited to share their experiences of using technologies. Students were recruited using both purposive (trying to ensure a range of disabilities and experiences were represented) and convenience sampling methods (e.g. contacting students known to either the core network members or the host university) involving email or face-to-face approaches. In total, 17 disabled students participated; 11 women and 6 men. All participants were adults, aged between 18 and 60. At the Seattle symposium four students participated who were members of the University of Washington DO-I T programme. At the Montréal symposium six students participated. At the Tel Aviv symposium five students participated. At the Hagen symposium two students participated via recorded video. At the Milton Keynes symposium 6 students participated. Across the total sample, a range of disabilities were represented including: blind/visually impaired; hearing impairment; mobility impairment; mental health and learning disabilities (e.g. dyslexia). Some students were living with more than one disability and therefore had complex support needs. In line with a social model of disability approach to working with disabled students and the principles of participatory research with disabled students (See Seale 2014 for comprehensive introduction overview of their merit) we did not assess students in order to confirm the 'label' they assigned to themselves.

\subsection{Procedure}

In advance of each symposium the core network members agreed a set of questions for the students to address, which aligned to the theme of the symposium (models, stakeholders, design, transition, new solutions) and also covered the following core

Table 1 Data collection sites

\begin{tabular}{lll}
\hline Date & Location & Theme \\
\hline March 14-15, 2017 & Seattle, Washington & Effective models and frameworks \\
May 30-31st, 2017 & Montreal, Canada & New stakeholder perspectives \\
March 13-14, 2018 & Tel Aviv, Israel & New designs \\
October 16-17, 2018 & Hagen, Germany & New practices for effective transition \\
June 11-122,019 & Milton Keynes, UK & New solutions \\
\hline
\end{tabular}


issues: 1.What are the benefits of ICT use for disabled students? 2. What is wrong with current ICT design for disabled students? 3. How can we improve ICT design for disabled students?

The students were provided with the questions in advance in order to prepare their answers. In Seattle, Montreal and Tel Aviv the panel was organised as a Question and Answer session where a chair person asked a question and then each student responded in turn. In Hagen (a part-distance university) the students were unable to attend in person so a pre-recorded video was presented in which the host of the symposium asked each student a set of prepared questions. In Milton Keynes (a wholly distance university) the students attended in person, and each spoke to a PowerPoint presentation that the hosts had helped them prepare in advance. The student panels held in Seattle, Montréal and Milton Keynes were audio recorded. The videos presented in Hagen were captioned for accessibility purposes which in turn delivered a transcript which could be analysed. Live notes were taken at the Tel Aviv Panel.

\subsection{Data analysis}

Initially, all the recordings of student panels and videos were transcribed by the researchers in order to generate a relationship within and between the data and the analysis. Secondly, using the iterative process of categorical analysis (Coffey and Atkinson 1996), the whole dataset was inductively analysed. This process facilitated the emergence of broad categories regarding barriers and enablers of students' use of technologies. Finally, a connecting analysis (Maxwell and Miller 2008) was undertaken in order to identify relationships that tied the data together into a narrative. In our analysis, we have been careful not to automatically assume that the disabled students were a homogenous group. We have therefore been open to the possibility that students with different disabilities can experience substantial variation in terms of their technology related experiences. However, our analysis did not suggest any variation, rather it revealed common experiences across the different 'disability categories', which we will present in the following section. Finally, in order not to privilege one student's voice or a group of student voices over others, when presenting our results, we have deliberately sought to use quotes from all five countries. Therefore, when presenting quotes, we will identify where the student was located in brackets (Milton Keynes, Montreal, Hagen, Tel Aviv, or Seattle).

\section{Results and discussion}

In this section we will consider the extent to which the outcomes of our analysis answer our three research questions and compare our findings to those in the existing literature.

\subsection{What are the technology related experiences of disabled students studying in the US, UK, Germany, Israel and Canada?}

Our research revealed a similar blurring or blending of technology use to that identified by Seale et al. (2008) and Fichten et al. (2020). Participants reported using a variety of both mainstream and specialist (AT) technologies. Examples of mainstream 
technologies included hardware and devices (PC, laptops, tablets); smartphones and MP3 players; applications and software such as smartphone apps, Google apps and pdf readers. Examples of specialist (assistive) technologies included software such as: screen-reading software, speech recognition software, mind-mapping software and devices such as Braille readers, scanners, voice recorders and DAISY players (reads books to visually impaired users). Our categorical analysis identified broad consensus across all the disabled students regarding the benefits and outcomes for them of using technology.

\subsubsection{Benefits of using technology}

Students commented on the functionality of the technology, specifically how it helped them to study. Technology was reported to help students access and read lecture and course material, record lectures, and produce summary notes of lectures and books. Some participants commented on how technology also helped them to adopt a studystatus (part-time or full-time) that suited their needs. Students also commented on how technologies improved their study efficiency, helping them to read or write faster and therefore saving them time:

Technology has completely changed my way of learning, without it, I would not be able to succeed as a student at all. I have visual impairment and after two pages I read I get tired. The screen reader allows me to "read" all the books and articles in each course (Tel Aviv).

I guess for me it was the Access technology specialist when I was in the C-GEP at university. I was through them that I learnt that technology existed to begin with. I was like, my God, it's taking me forever to read this text book, there must be a better way and they said "Well-yes we have this Win program- here's a scanner, scan your book into the program and it reads it to you (Montreal).

I've been using technology in school since third grade when I started using the computer to type since it was a lot faster than writing. I've used a laptop most of my high school career, and I got a Microsoft Surface in college, which was much lighter and allowed me to use my technology independently (Seattle).

These results echo those of Seale et al. (2010) who noted that for the students in their study the most frequently mentioned affordance of technology was the efficiency it offered them in terms of organisation of time; organising essays; and finding references and information quickly.

\subsubsection{Outcomes of using technology}

There was also acknowledgement that technology contributed towards student's success in achieving a qualification or passing an assignment. Such success enabled them to achieve their academic potential:

My journey has been successful. I gained two honours degrees in 2017 and I am in year 2 of my Masters in online and distance education. But without accessible 
materials, accessible equipment and the support of fellow students, my journey would be totally finished (Milton Keynes).

Without technology, I could not achieve my assignments through the courses I completed so far, and frankly, maybe I could not even be a university student. In high school I took the lowest class of math, and not because I was terrible in math or just lazy. The main reason was that I could not write math by hand or type it on the computer, and it is quite impossible to study math if you cannot practice it. A few years later, I am a student of economics, with a pair of math courses in my record. What made it possible? Technology (Tel Aviv).

In class, video lessons, in which every student can participate from home, or watch the recorded lesson later, how many times as desired. Video lessons turn the disability into an ability - the ability to succeed. (Tel Aviv).

Technology gives me the ability to progress, to succeed, to express myself and utilize my potential.

The screen reader enables me to succeed in my studies and fulfil my potential at work (Tel Aviv).

For many students, a key consequence of being able to study and succeed was being independent and therefore liberated from being a burden on others:

If the technology is employed in class is sufficiently accessible then I feel free. But if not I feel like I am confined... my ability is limited because of technology. But there is another issue: I feel burdened to ask the professor to change the technologies that is being used just because of me. To be honest I feel a little bit guilty, even though it is my right. And between professors and students, it is not easy. If the professor is not willing to accommodate or find another solution, the effect is far reaching (Seattle).

With the help of screen-reader software called 'Jaws' which converts the script into audio output and allows independent learning, I also use a recorded book, so I learn and prepare for the test independently (Tel Aviv).

These non-academic outcomes are quite different from the psycho-social outcomes measured and captured by Heiman and colleagues (Heiman and Olenik-Shemesh 2012; Kaspi-Tsahor et al. 2011); although it is possible that feelings of independence and being less of a burden could contribute to hope and well-being. In terms of further research it would certainly be interesting to explore the extent to which levels of freedom and burden could be measured and the extent to which such measurements help higher education institutions improve the technology related support they offer to disabled students.

\subsection{What, if any, difficulties do disabled students studying in US, UK, Germany, Israel and Canada experience regarding technology access and use}

Our categorical analysis identified broad consensus across all the disabled students regarding the difficulties they experienced accessing or using technologies. They 
reported difficulties associated with: i) the design of technologies ii) a lack of 'technological know-how' and iii) a lack of social capital.

\subsubsection{Difficulties associated with the design of technology and systems related to technology provision}

The students across all five countries commented on the poor design of technologies. Some comments were specific to certain specialist or mainstream devices:

One of the problems I encountered with the use of the courses' websites is that the lecturers upload inaccessible presentations containing scanned graphics that my screen reader cannot read. Not always because of resistance, unwillingness to help or lack of empathy, some of them are rather old people who are less familiar with the new technologies. Perhaps the university should provide them assistants who knows all the technologies (Tel Aviv).

I think the main problem that I have had in being at school with a disability is that often software is not accessible on the technology that I use. I am a quadriplegic and I don't have the use of my hand- so using the computer for me is extremely hard and I do everything on my iPad. But often software like Word, Excel IMovie don't have as much features on the iPad as they have on the computer. So I have to ask people for help, like my parents and it just makes everything harder and I have to spend twelve more hours than I should have- on work that should take three hours. That is the main barrier (Montreal).

Some comments focused on technical inaccessibility of websites and online courses:

The websites I have got some barriers sometimes. There are special prescriptions how to make website accessible for blind people. This is the one thing not all websites are very really free of barriers. Without outside help it's difficult sometimes (Hagen).

One student described how in one of her Masters module she is required to work with a group to build a web-site. It is worth $28 \%$ of the marks. However the platform she is required to use is not accessible. So she has to ask her care assistant to upload her contribution to a site, and then someone else in the group has to put onto the website for her:

"I do feel included, but I also feel a burden". [...] "I should be able to do that myself. They shouldn't be giving us something to do, that I can't access as well (Milton Keynes).

Other students reported problems when updates to apps and programs 'break' what was functioning normally (prior to the update); when ATs don't keep up with the latest 
versions of browsers and when documents are not automatically converted into an accessible format:

Over the years, the OU has changed to many online tutorials instead of face-toface and for me Adobe Connect isn't very accessible. My screen-reader doesn't read the white-board. OU Help- it's available- except at 3 o'clock in the morning when I study. But a success that they have developed is SensusAccess which translates information into accessible formats that I can listen to. I love the library for that. Brilliant! (Milton Keynes).

Over the years, Windows has evolved, and 'Jaws' software has not kept up. In order to keep on working at my workplace I had to spend a lot of money in order to be updated with the new additions (Tel Aviv).

Whenever there is a new software update in the market, it takes me a lot of time and effort to get used to the new changes, and to understand the advantages of the software (Tel Aviv).

The findings regarding poor design of technologies replicate the results of other studies where disabled students have complained about the inaccessibility of technologies they are expected to use (e.g. Unterfrauner and Weiermair-Märki 2008; Gerrard 2007; Asuncion et al. 2012). The problems regarding technology updates has not been previously identified.

Students also made interesting comments about how some technologies were too expensive for them and that they could not afford them without financial assistance from government schemes such as the Disabled Students Allowance (DSA) in the UK and the National Insurance Institute in Israel.

As a student the programs are very expensive. You don't really have a lot of money unless you are lucky enough to get some kind of government grant- or your university somehow manages to get you a copy of the program that you can install on your device (Montreal).

You have these computer programs which are either very limited in where you can get them- because they are installed on one computer in one place that has 9-5 0r 9-10 hours and after these times you are stuck- or you have to figure out how to get a copy yourself either by getting an illegal copy or by spending lots and lots of money to acquire a legal copy. I think that is a huge barrier (Montreal).

Findings such as these are particularly significant when taken together with data that shows that for disabled students concerns over money may lead some to abandon their studies. For example, Martiniello et al. (2012) reported that thirty participants (7\% of current students, $8 \%$ of graduates, and $14 \%$ of those who left their program of study without graduating) in their study cited disability-related financial concerns as an obstacle. The expense of some technologies may explain why many disabled students seek low cost alternatives (Seale et al. 2008; Fichten et al. 2020). We will re-visit this issue in the next section when we explore disabled students suggested solutions to their difficulties. 


\subsubsection{Difficulties associated with a lack of 'technological know-how'}

In a study that explored the technology experiences of 31 disabled students studying in one university Seale (2013) argued for the existence of something she called 'digital cultural capital'. The acquisition of digital cultural capital is exemplified by disabled students in her study investing time in improving their technology knowledge and competencies through informal or formal learning opportunities, as well as a socialization into technology use and 'techno-culture' through family, peers and media. Seale (2013) labelled these technology knowledge and competences 'technological knowhow' and Seale et al. (2015) offered the following as examples of the 'technological know-how' of disabled students in their study of the experiences of 175 disabled students: using a range of technologies to support learning; developing strategies for using generic and specialist technologies to enhance learning efficiency, being aware of the pros and cons of using technologies and being confident to use technology to support learning. There was certainly evidence from the disabled students in the study reported here of a certain level of 'technological know-how':

When I find new software or an app that I think can help me- I think I just have to go on YouTube and everything is out there that is well-explained or on Google. I think everything can be simply explained on YouTube. You can just look it up. In my opinion I don't need someone to necessarily show me- I can just look at the video for 2 minutes and then OK I get it (Montreal)

I had to train myself in a screen reader and refreshable braille display, which has very different keystrokes than Korean tools. I have a unique challenge of not only being blind, but learning a new language when I came to America (Seattle).

I am completely self-taught. In every assignment I learn something new about the software (Tel Aviv).

I taught myself to use most technologies. It's all trial and error (Tel Aviv).

This reflects the findings of Seale et al. (2010); Seale (2013) and Seale et al. (2015) and is important as it counteracts the dominant negative stereotype of disabled students as lacking in ability. Nevertheless, despite this, analysis of the experiences shared by disabled students in the study reported here, also suggest that lack of 'technological know-how' on occasions did present a significant barrier to their successful use of technologies. Participants talked, in particular of the influence that lack of awareness of and familiarity with technology, particularly in the early stages of their study:

Just because you are a user of technology, doesn't mean you are an expert. Students don't always have a good solid understanding of what it means to encounter an inaccessible or unusable website [...] Part of that ability to access and use technology is knowing when to use it-because sometimes it may not be the best tool to use for a specific task. Sometimes you may prefer using braille or large print and that's OK- it's important to know that these are a tool-box of resources. That's really key. Students need to learn when and when not use specific technologies. Part of that is also ensuring that you have early intervention 
and rehabilitation professionals to ensure that students don't develop learned helplessness- because part of using technology and navigating the Internet involves the ability to problem-solve and take the initiative- something that is not always there (Montreal).

My overall experience is positive. But, as a non-technical person I struggled during my first year when I didn't have the technology and also when I first got it. It took me a good six months, via training and constant use, to become comfortable with the technology (Milton Keynes).

This lack of awareness and familiarity was often linked to lack of information about the technologies:

Either it's finding the technology- because either there is tonnes of stuff out there that you just don't even know exists- just because no-one has introduced it to you- or you haven't spent hours looking it up or it's something new on the market. It might be the best thing out there but if no-one knows it exists it's kind of hard to access it (Montreal).

I heard the things that were said by the student who spoke before me and realized that I did not know some of the technologies she mentioned even though this is my second year as a student. I think there is not enough information about it at the university (Tel Aviv).

Echoing the findings of Seale et al. (2010) disabled students in this study also identified time as a major factor that influenced their study and technology experience. In particular, there was an implication that obtaining 'technological know-how' sometimes came at a cost:

I just have to end up taking out time in my schedule from extra-curricular activities just to cope... I'm fine with that, I'm used to being flexible with my schedule... So yes... we do spend a lot more effort to complete what we need to complete versus somebody else without challenges and many people don't realise that as a part of the need for accessibility (Seattle).

Seale et al. (2010: p 458) argued that time is a critical criteria when disabled students are making decisions, about their technology use because answers to questions such as "how much time will I have to commit to learning to use this technology?", and "can I afford to divert this time away from studying?" might override answers to potentially more important questions such as "is it the right or appropriate technology to use?" or "does it work?"

\subsubsection{Difficulties associated with a lack of social capital}

In addition to arguing for the existence of 'digital cultural capital', Seale (2013:p3) also used her data to identify a phenomenon she called 'digital social capital'. She defined this as the 'networks of 'technological contacts' and support that people have, which can be face to face (e.g. family, friends, tutors) or remote (e.g. online help facilities)'. 
The experiences shared by disabled students in the study reported in this paper suggest that lack of 'digital social capital' caused them some difficulties in using or accessing technologies to support their learning. The sources of 'digital social capital' that they talked about included faculty, those in student support services and peers.

Although the students did offer examples of how faculty awareness of technology had enabled them, it was more common for them to talk about how faculty lacked awareness and/or were unwilling to provide support:

[...] I was always surprised at how my teacher would look at me- when I would say- oh I'm quadriplegic I don't have use of my hand. They would be like, what do you mean you don't have use of your hand? So I would say, I need to use my iPad and they would say- 'but that's like cheating!' and I would say, well other than that I can't do your class. Eventually, we would work something out. But I think teachers should be a little more aware of the technology and what is out there and what they can offer me for their classes (Montreal).

However, the accessibility barrier comes in place when attitudes opinions and knowledge is concerned, and prejudices. A very good example of this is that I sent an introductory email to my tutor at the beginning of last year. Just to say hello- if you have me in your tutorial can you please send me your slides in advance so that I can read them along with everyone else, because I won't be able to read what is on the screen- I'm blind. Her reply was "Hi give me your address and I will print them out and post them to you!' I was like- I've just told you that I am totally blind- I'm sorry but what?! They weren't really listening or understanding me, [...] (Milton Keynes).

(At the student's institution) most professors don't want to provide their notes to students [...]. Even with the professors that are willing to provide slides to me... they make modifications (to the slides) up until they walk into the lecture. Or sometimes they spill into (the content of) another lecture and they don't put those slides in the set they send to you. So I've experienced times where I miss out on quite a bit because... those pieces aren't there. Then... (they will say) "oh well if you wait until lecture so-and-so, they are in that set" ... it's a little bit late to complete any work that I need to do. (Seattle).

There are lecturers who are willing to help but not all of them. I once asked one of the professors to send me the presentation in an accessible file in advance so I could hear it before the Lecturer and he refused. He claimed he didn't want the presentation to be available to the students. I couldn't make him understand that for me it was the only way to learn what he wanted me to know (Tel Aviv).

The students were much more positive about the support they received from those working in student services such as access technology specialists or librarians. The students appreciated the knowledge that they had of technologies:

You've got some great people specialising in screen-reader use. I had some trouble getting to speak to one at the beginning, but once I had, both members of staff have been fantastic and I really appreciate their help (Milton Keynes). 
I guess for me it was the Access technology specialist [...]. It was through them that I learnt that technology existed to begin with. I was like, my God, it's taking me forever to read this text book, there must be a better way and they said "Wellyes we have this Win program- here's a scanner, scan your book into the program and it reads it to you. And then later on [...] it was- give us the textbook and we will scan it on your behalf and give you an electronic copy. At the time it was on a disk and now it is emailed to you. And if you had any problem or questions you could go there and say look the program is not working for me -help me. They knew the ins and outs of the program (Montreal).

Just giving me the software is like throwing me into the water and thinking I'll be able to swim. I would not have been able to learn to use the technology without the technological instructor provided by the university (Tel Aviv).

The students also appreciated the accommodations that those in student support services provided:

All my needs have been listened to and met- by the student support team- Tutors are a different story sometimes. Books are accessible. All the online resources are absolutely fantastic. I come from mainstream education where I had to fight for access to my books and wait for 3 months for a complete textbook to be sent to me electronically. The OU is absolutely amazing in that regard- you get your pdf and you get your Daisy stuff and it's great (Milton Keynes).

Librarians specializing in accessibility who are responsible for making documents accessible. Having a librarian who is assigned this role would be very beneficial for colleges and universities (Montreal).

The university's technical support helped deal with changes in the website. (Tel Aviv).

One aspect that that campus-based disabled students did not find particularly supportive, was where those in student services chose to locate technologies that were intended for disabled students to use:

Some technologies were not very advanced at that time. Some were hard to use, not very intuitive. Especially technologies for the blind and visually disabled were often stationary and tied to specific locations that means it wasn't like today where you can use smartphones with voice output which is portable and for everyday use. Like smartphones today. It was located in special offices or in the library (Hagen).

It would be to make computers more accessible for people like me how don't have use of their hands because I cannot use computers like everyone else. So to have alternatives to computers like iPads or tablets or something. Also, I just can't fit into the labs- If I could go myself it would be much easier, because I always have to ask my friends to print stuff for me or I had to do it at home (Montreal). 
These experiences are rather different to those reported by Fichten et al. (2010b) and Seale (2014). Students in these studies comments on the lack of availability of adapted computers in campus-based computer laboratories (Fichten et al. (2010a, 2010b) and the sense of 'ghettoization' they felt by having to access their assistive technologies in segregated spaces on campus.

The experiences shared by the participants in this study suggest that disabled students valued the support provided by peers:

Sometimes it is easier on the peer level to show something. You talk differently with each other, can try things out together. The institutional support can teach the basics (Hagen).

Sometimes this support was from other disabled students:

Peer support- peer-teaching support. Learning from other users. We have seen quite a bit of this since mainstream technology has been developed over the past 5-10 years. There are great website resources maintained by users with VI to help each other. Sometimes this is the greatest source of information, because you can learn a more efficient way of doing something (Montreal).

I have made connections with other blind students to find solutions. (Seattle).

Other times, the support was from the wider student cohort:

Also [...] without fellow students supporting me on-line, I would have given up. Because someone is usually available $24 / 7$, because we have students from around the globe. So for me adapted technology is important, but sometimes it is not totally fit for purpose. My main mental health is my fellow peers who are sitting around this table with me. In todays' online world, a friendly voice when you are at your lowest, is worth more than all the technology that I have available (Milton Keynes).

We're supporting each other. We all have different previous experiences, in different areas, I cannot definitely say: I learn this way... We develop specific skills together or I am supported by someone or support others. It always depends on the individual case (Hagen).

Sometimes the focus of support was 'how to use' a particular piece of technology:

I wonder if a lot of good knowledge is being lost because we don't think in a joined-up way across the modules. I'm interested in technology, particularly assistive technology. I've answered a couple of Jaws-related questions when I've seen them in the Facebook groups, but I'm wondering whether there's more that we could do in terms of helping new students by having student leads or contact people in relation to working with certain types of access technology.[... 
]. Of course, we won't have studied the same modules, but there are definitely tips that I could pass on about things that have made life easier (Milton Keynes).

When I was at school they were hiring students to be champions of ProQuest (a research database). They would train these students and then these students would organise training sessions with other students to promote ProQuest. I guess that is great for ProQuest, but not so great if you want to do anything outside of that database. Peers are nice- because you get to know your colleagues and how they like it- but at the same time you also have that bias (Montreal).

Sometimes disabled students used technology as the medium through which support was provided:

All the students in the program are in the WhatsApp. Throughout the week we can refer questions to the counsellor or to each other. Sometimes someone has already registered through the site and can explain to the others what to do (Tel Aviv).

Also, the Disabled Students Group and social media are very important to me, because without fellow students supporting me on-line, I would have given up. Because someone is usually available $24 / 7$, because we have students from around the globe. So for me adapted technology is important, but sometimes it is not totally fit for purpose. My main mental health is my fellow peers who are sitting around this table with me. In todays' online world, a friendly voice when you are at your lowest, is worth more than all the technology that I have available (Milton Keynes).

Whilst peer support was highly valued by disabled students- there were no suggestions that they wanted to replace the support of faculty or student services with peer support. Peer support appeared to be valued as an additional source of support, thus echoing the findings of Seale et al. (2015).

\subsection{What potential solutions do disabled students studying in US, UK, Germany, Israel and Canada propose might address these difficulties?}

In conducting an analysis that sought to connect all the different categories that we identified in our data we noticed that when disabled students talked about potential solutions to the technology related difficulties that they experienced their language reflected two particular kinds of 'Futures Thinking' (Black 2012): Preferable Futures and Possible Futures. Black (2012) applied a 'Futures Thinking' lens to her examination of the tensions between mainstream and special schooling for children with special educational needs. In seeking to define and understand 'futures thinking' Black (2012) conducted a literature review and, extending the descriptions of Marien (2002), highlighted six categories of 'Futures Thinking'. Seeing the potential value of this lens, Seale (2020) applied these categories to field of technology, disability and Higher Education and argued that key stakeholders were implicitly applying five of the six approaches (See Table 2). 
Table 2 Five categories of 'Futures Thinking'

\begin{tabular}{|c|c|c|}
\hline Category & Focus and description & Typical methods and outcomes \\
\hline $\begin{array}{l}\text { Present } \\
\text { changes }\end{array}$ & $\begin{array}{l}\text { Analytical: identifying present trends; } \\
\text { Identifying and monitoring change. }\end{array}$ & $\begin{array}{l}\text { Historical analysis, indicators, trend } \\
\text { spotting, emerging issues analysis }\end{array}$ \\
\hline Questioning & $\begin{array}{l}\text { Philosophical: dissenting, reformulation and } \\
\text { serial futuring. }\end{array}$ & $\begin{array}{l}\text { Critiquing, deconstruction and } \\
\text { reformulation. }\end{array}$ \\
\hline $\begin{array}{l}\text { Probable } \\
\text { Futures } \\
\text { What will be }\end{array}$ & $\begin{array}{l}\text { Strategic: Looking at trends and drivers to } \\
\text { predict the most likely future within a } \\
\text { given period, under a specific set of } \\
\text { contingencies. }\end{array}$ & $\begin{array}{l}\text { Forecasting, predicting, exploring drivers for } \\
\text { change, extrapolating trends. List of } \\
\text { recommendations that will achieve a } \\
\text { particular vision of the education system } \\
\text { required to respond to these trends and } \\
\text { recommendations. }\end{array}$ \\
\hline $\begin{array}{l}\text { Possible } \\
\text { Futures } \\
\text { What could be }\end{array}$ & $\begin{array}{l}\text { Creative: Imagining alternative futures, } \\
\text { regardless of how 'far out' they may } \\
\text { seem. }\end{array}$ & $\begin{array}{l}\text { Scenario construction, risk analysis and } \\
\text { deductive forecasting. Scenarios and } \\
\text { responses to those scenarios. }\end{array}$ \\
\hline $\begin{array}{l}\text { Preferable } \\
\text { Futures } \\
\text { What should be } \\
\text { or what we } \\
\text { ought to do }\end{array}$ & $\begin{array}{l}\text { Subjective or values- driven; based on what } \\
\text { people want to happen. Peoples hopes } \\
\text { aspirations and dreams regarding im- } \\
\text { proving the future (typically by requiring } \\
\text { a change or restructuring of the current } \\
\text { education system in order to be achieved). }\end{array}$ & $\begin{array}{l}\text { Planning, strategizing and visioning } \\
\text { Descriptions of best practices that reflect a } \\
\text { notion or a vision of a preferred future. }\end{array}$ \\
\hline
\end{tabular}

In our study, from our connecting analysis of what disabled students shared about their experiences, we noticed that occasionally they adopted the discourse of 'Preferable Futures' when talking about design solutions to the poor practice of faculty:

\begin{abstract}
Module teams should be taught, trained, and be required to think about accessibility as a first thought not an after-thought when writing modules. I am sure that there are students who would be willing to sit down and discuss directly with module teams during their module writing processes how to improve accessibility and what to expect in terms of requests for alternative formats and requirements to meet the needs of all students. (Milton Keynes)
\end{abstract}

We were however, struck by the more prevalent use of a 'Possible Futures' discourse by the disabled students. In thinking about design solutions, they imagined alternative futures where the practices of technology companies, faculty and institutions as a whole changed. In thinking about solutions to address difficulties associated with the design of the technologies and a lack of technology know-how the students imagined changes in how new technologies were developed by technology companies and other stakeholders, but also how they were then marketed or shared with disabled students to enable them to make empowered, informed decisions about whether to obtain and use the technologies:

Because sometimes what I find is that technologies are developed that certainly don't respond to my needs and the needs of those around me. There is a lot of 
diversity in our community but I think that we would be far more efficient if we could work with researchers and developers from the start (Montreal).

Free trials of software would help us. (Milton Keynes)

In thinking about solutions to address difficulties associated with the design of the technologies, a lack of technology know-how and a lack of social capital, the disabled students imagined futures where institutions asserted their economic power, transformed the spaces they made available to faculty and students and eliminated traditional bureaucratic practices:

I realise I am a blind person, dreaming in colour, but I am going to say this anyway. Think about the impact, if an institution decided if they once a year would refuse to use books where accessible content had not been provided. If an accessible copy is not available or obtainable- a faculty member decided that they would not use that book in their classrooms. I sincerely think that if we had that kind of support, things would change. I think we need to start thinking about these kind of policy level aspects to the problem. (Montreal)

Creating an accessibility zone that is available to students and professors- an open and safe environment that allows students and professors to receive support, including practical workshops, and to exchange ideas and come up with solutions to accessibility problems together. (Montreal)

I was thinking that we also need to work with publishers because they don't always talk to people with disabilities directly. Sometimes, they have to go through the disability office and that is a lot of red-tape. I think that as valuable customers of publishers, we need to find some way to interact with them better and get rid some of the red-tape in order to get acceptable contact (Montreal).

A strong recurring theme across all the identified 'Possible Futures' was that of improving communication between different stakeholders and brokering connections:

Another very big problem is that after finishing studying that nobody knows anything about this technology. When you go to work market, to labour market after finishing the university and you apply for certain jobs, nobody could really imagine how blind people work similar to people with no disabilities. And this absence of information, it's a very big problem everywhere [in] the normal world I think [..] Once more I want to say that the university could play a role and make the technology more known in the public maybe. Get into contact with companies where this technology is presented. Maybe this would be nice idea to produce more knowledge about the possibilities - existing possibilities. And the university would be kind of - a kind of connector between learning and applying for jobs. Something like that (Hagen).

We need to find more efficient ways to obtain accessible material. I would like to see a national database or a more efficient way of communicating with other institutions so that we have access to content that they have already scanned elsewhere. We could certainly make the process more efficient if we started thinking about how we collaborate (Montreal). 
At first glance some of the solutions imagined in these alternative 'Possible Futures, might not seem to be 'far out' or 'pushing the boundaries' in that they have been talked about before. For example, the idea of students working with designers and developers from the beginning of the design process (participatory design) is not a new idea. Participatory design can be defined as active involvement of users throughout the entire research and development process (Hanson et al. 2007) and is generally understood to involve: working directly with users; early and continual participation of users; engaging with real users in their real contexts; iterative cycles of development and evaluation until an agreed solution is reached and collaborative partnerships between users and designers. Participatory design methods are varied but have a strong ethnographic tradition with regard to conducting intensive observations of the user and how they use technologies in their everyday lives (Davies et al. 2004). The strong narrative and in-depth insights offered by participatory design methods would appear to be highly applicable to design practices that are attempting to be empathic by hearing the 'disabled student voice' in relation to their technology ideas, preferences and experiences. For example, Gkatzidou and Pearson (2011) adopted a participatory approach to the design of personalised learning applications in a project called WIDE (Widgits for Inclusive Distributed Environments). Researchers and technologists worked together with disabled students and practitioners (in teaching or support roles), to identify a student need and to explore the potential solutions to that need. The ideas were then translated into a design document, which represented a learning design for a widget that would best support the student. The WIDE development team then produced iterative prototypes of the widgets in close cooperation with the designers to produce a bank of widgets that could be incorporated into a range of learning environments, developed by and for those responsible for supporting disabled students in further and higher education and in specialist colleges. This example, is however, a very rare example of participatory design being applied in reality, rather than simply talked about. One reason for this, might be that participatory design is a very labour intensive process and requires a skilled inter-disciplinary team to implement the process in the full spirit of the underpinning principles. This gives technology companies an easy 'get-out clause' or excuse for not adopting participatory design approaches. But if researchers continue to enable disabled students to voice their preferences and imagine futures where participatory design does routinely happen, then what might emerge are solutions that address how to make this labour-intensive, interdisciplinary approach easier, smoother or cheaper.

Some of the solutions that disabled students in our study have explicitly imagined in their alternative 'Possible Futures' have prompted us to think about how technology companies might act differently. For example, in the data we have seen that cost and affordability of technologies is an issue for disabled students. It therefore makes sense that a potential solution imagined by disabled students is that of free trials. Indeed, the provision of free trials is a standard business model used by the developers of mainstream products such as Survey Monkey and LinkedIn. Users can use the standard application for free, but if they want additional features they then have to pay for package upgrades. Other solutions that are implicit in our data, but not necessarily expressed as 'Possible Futures' relate to how technology companies might have a responsibility to extend their remit and contribute to the provision of training and technical support. For example, when students talk about the provision of an 
'accessibility zone' or the maintenance of 'a national database' it may be appropriate to consider how higher education institutions might collaborate with technology companies in order to realise such aspirations. For example, in the symposia disabled students talked frequently about how they liked to go online to find (or create) YouTube clips and other resources that would help them and others learn how to use their technologies:

When I find new software or an app that I think can help me- I think I just have to go on YouTube and everything is out there that is well-explained or on Google. I think everything can be simply explained on YouTube. You can just look it up. In my opinion I don't need someone to necessarily show me- I can just look at the video for 2 minutes and then OK I get it. (Montreal)

Nobody knows it. When you are not concerned with a disability or something like that, and you don't get [in] touch with it and I think this different. If you want, I can send you it later on a YouTube link where I tell how this technology I work with, how it works. (Hagen)

With this in mind, technology companies might therefore have a role to play in investing in programmes or approaches that help students to create open and easy to find online videos on how to use technology. They might also collaborate with universities to maintain and update an online database of technologies that students would find helpful; perhaps using existing apps or components of social media such as tags, likes, reviews or ratings. An alternative approach might be to invest in a scheme similar to that that described by a student from Montreal where the technology company that developed the research database ProQuest hired students to train other students how to use it. This training could be face-to-face, but evidence from our data suggests a strong preference for online training or peer support.

\section{Conclusions}

In this paper we have argued that in the field of disability, technology and higher education solutions to the learning challenges that disabled students face should not just focus on the design of technologies, but should extend to the design of practices within higher education institutions. In addition, we have argued that disabled students themselves should have a voice in debates regarding what particular design solutions are needed in order to improve these practices. In order to support our argument, we have presented findings from a study that analysed the perspectives of disabled students studying in the US, the UK, Germany, Israel, and Canada, regarding their experiences of using technologies to support their learning.

Our results revealed common experiences and views regarding potential design solutions. There were no obvious differences between the five countries or between students with different disabilities. The pattern that we identified was that the disabled students were able to identify examples where the functionality of the technologies had supported them to study and enabled them to achieve their academic potential. Despite these positive outcomes, the students also reported difficulties associated with: i) the 
design of the technologies, ii) a lack of technology know-how and iii) a lack of social capital. When identifying potential solutions to these difficulties the disabled students imagined both preferable and possible futures where faculty, higher education institutions, researchers and technology companies are challenged to push the boundaries of their current design practices.

Our research with disabled students from the US, UK, Germany, Israel, and Canada has made three particular contributions to knowledge. Firstly, the results reported in this paper support the findings of earlier studies regarding the existence of the 'doubleedged sword' phenomenon. Whilst the disabled students in our study shared examples where technology facilitated positive outcomes for them, they also reported the existence of a wide range of barriers to or difficulties in using these technologies. The results of this study therefore indicate that this phenomenon is both persistent and widescale (i.e. not unique to one country).

The second contribution of the study is that it has enabled disabled students themselves to identify potential solutions to the difficulties they experience (e.g. free software, a national database of technologies and an accessibility zone). These solutions differ considerably from the solutions identified by other research (e.g. Universal Design and training of faculty) which has tended to focus on the issues from a faculty or institutional perspective. They therefore extend the repertoire of potential solutions that future research might investigate further.

The third and final contribution of the study is that it suggests there is a need for solutions that deliberately and unashamedly push stakeholders such as faculty, higher education institutions and technology design companies beyond their comfort zone. A 'Future Studies' lens, with its emphasis on creative and aspirational imagining of alternative futures may therefore offer a useful framework to continue pushing the boundaries of design practice. In doing so, future research will benefit from engaging a larger sample of disabled students than the one reported in this study and in exploring Future Studies methods (See Table 2) in more detail. For example, there may be value in applying the 'scenario construction' method (Black 2012) whereby the experiences of disabled students are distilled into scenarios or what future practice might look like, which practitioners and higher education institutions are then supported to engage with in order plan strategically for how to make these visions of the future a reality. Furthermore, given that our results also revealed that participatory design was identified as a desired or potential solution there is value in exploring the extent to which disabled students might collaborate with practitioners and higher education institutions in this strategic planning.

Open Access This article is licensed under a Creative Commons Attribution 4.0 International License, which permits use, sharing, adaptation, distribution and reproduction in any medium or format, as long as you give appropriate credit to the original author(s) and the source, provide a link to the Creative Commons licence, and indicate if changes were made. The images or other third party material in this article are included in the article's Creative Commons licence, unless indicated otherwise in a credit line to the material. If material is not included in the article's Creative Commons licence and your intended use is not permitted by statutory regulation or exceeds the permitted use, you will need to obtain permission directly from the copyright holder. To view a copy of this licence, visit http://creativecommons.org/licenses/by/4.0/. 


\section{References}

Advance HE. (2018). Equality and higher education: Students statistical report 2018. Resource document. Advance HE. https://www.ecu.ac.uk/publications/equality-higher-education-statistical-report-2018/

Alahmadi, T., \& Drew, S. (2017). Accessibility evaluation of top-ranking university websites in world, Oceania, and Arab categories for home, admission, and course description webpages. Journal of Open, Flexible and Distance Learning, 21(1), 7-24.

Ari, I. A., \& Inan, F. A. (2010). Assistive technologies for students with disabilities: A survey of access and use in Turkish universities. The Turkish Online Journal of Educational Technology, 9(2), 40-45.

Arim, R. (2017). A profile of persons with disabilities among Canadians aged 15 years or older, 2012. Resource document. Statistics Canada, catalogue no. 89-654-X. http://www.statcan.gc.ca/pub/89-654x/89-654-x2015001-eng.pdf.

Asuncion, J. V., Budd, J., Fichten, C. S., Nguyen, M. N., Barile, M., \& Amsel, R. (2012). Social media use by students with disabilities. Academic Exchange Quarterly, 16(1), 30-35.

Baldiris Navarro, S., Zervas, P., Fabregat Gesa, R., \& Sampson, D. G. (2016). Developing teachers' competences for designing inclusive learning experiences. Educational Technology \& Society, 19(1), 17-27.

Bishop, D., \& Rhind, D. J. A. (2011). Barriers and enablers for visually impaired students at a UK higher education institution. British Journal of Visual Impairment, 29, 177-195.

Black, A. (2012). Future secondary schools for diversity: where are we now, and where could we be? $\mathrm{PhD}$ Thesis. Exeter University.

Blankfield, S., Martin, L. (2002). Are we getting it right? A widening participation project. Online. Available: http://www.lancashirecompact.ac.uk/reportspapers/gettingitright.pdf (accessed 5 October 2005).

Bouck, E. C., Maeda, Y., \& Flanagan, S. M. (2012). Assistive technology and students with high incidence disabilities: Understanding the relationship through the NLT2. Remedial \& Special Education, 33(5), 298-308.

Brandt, S. (2011). From policy to practice in higher education: The experiences of disabled students in Norway. International Journal of Disability, Development and Education, 58(2), 107-120.

Burgstahler, S. (2015). Universal design of instruction: From principles to practice. In S. E. Burgstahler (Ed.), Universal design in higher education: From principles to practice (2nd ed., pp. 31-64). Boston: Harvard Education Press.

Burgstahler, S., Havel, A., Seale, J., \& Olenik-Shemesh, D. (2020) Accessibility framworks and models: Exploring the potential for a paradigm shift. In Seale, J. (Ed). Improving accessible digital pracices in higher education: Challenges and new practices for inclusion. Palgrave Macmillan. Cham, Switzerland. pp. $45-72$.

CAST. (2018). Universal Design for Learning guidelines version 2.2. Resource document. CAST. http://udlguidelines.cast.org.

Center for Universal Design. (1997). The Principles of Universal Design. Retrieved from http://www.ncsu. edu/www/ncsu/design/sod5/cud/about_ud/udprinciplestext.htm

Claiborne, L. B., Cornforth, S., Gibson, A., \& Smith, A. (2011). Supporting students with impairments in higher education: Social inclusion or cold comfort? International Journal of Inclusive Education, 15(5), $513-527$.

Coffey, A., \& Atkinson, P. (1996). Making sense of qualitative data, complementary research strategies. London: Sage Publications.

Davies, R., Marcella, S., McGrenere, J., \& Purves, B. (2004). The ethnographically informed participatory design of a PDA application to support communication. In proceedings of ACM ASSETS 2004 (pp 153160). Retrieved from http://www.cs.ubc.ca/ joanna/papers/ASSETS2004_Davies.pdf

Davies, C. (2007). Supporting Disabled Learners through the provision of assistive technologies in the further and higher education sectors. ATHEN E-Journal Issue 3 Retrieved from http://athenpro.org/node/89

DO-IT. (2016). 2016 report of the AccessSTEM/AccessComputing/DO-IT longitudinal transition study (ALTS). Resource document. Access Computing. https:/www.washington.edu/accesscomputing/2016report-accessstemaccesscomputingdo-it-longitudinal-transition-study-alts.

Eden, S., \& Heiman, T. (2011). Computer mediated communication: social support for students with and without learning disabilities. Educational Technology \& Society, 14(2), 89-97.

Fichten, C. S., Ferraro, V., Asuncion, J. V., Chwojka, C., Barile, M., Nguyen, M. N., et al. (2009). Disabilities and e-learning problems and solutions: An exploratory study. Educational Technology \& Society, 12(4), 241-256. 
Fichten, C. S., Asuncion, J. V., Nguyen, M. N., Budd, J., \& Amsel, R. (2010a). The POSITIVES scale: Development and validation of a measure of how well the information and communication technology needs of students with disabilities are being met. Journal of Postsecondary Education and Disability, 23(2), 137-154.

Fichten, C. S., Nguyen, M. N., Asuncion, J. V., Barille, M., Budd, J., Amsel, R., \& Libman, E. (2010b). Information and communication technology for French and English speaking postsecondary students with disabilities: What are their needs and how well are they being met? Exceptionality Educational International, 20(1), 2-17.

Fichten, C. S., Havel, A., King, L., Jorgensen, M., Budd, J., Asuncion, J., et al. (2018). Are you in or out? Canadian students who register for disability-related services in junior/community colleges versus those who do not. Journal of Education and Human Development, 7(1), 166-175 https://doi.org/10.15640/jehd. v7n1a19.

Fichten, C., Jorgensen, M., King, L., Havel, A., Heiman, T., Olenik-Shemesh, D., \& Kaspi-Tsahor, D. (2019). Mobile technologies that help post-secondary students succeed: A pilot study of Canadian and Israeli professionals and students with disabilities. International Research in Higher Education, 4(3), 35-50.

Fichten, C., Olenik-Shemesh, D., Asuncion, J., Jorgensen, M \& Colwell, C. (2020). Higher education, information and communication technologies and students with disabilities: An overview of the current situation. In J. Seale (Ed) Improving digital practices in higher education: Challenges and new practices for inclusion. Palgrave.

Gerrard, C. (2007). Virtual learning environments: Enhancing the learning experience for students with disabilities. Campus-Wide Information Systems, 24(3), 199-206.

Goodman, G., Tiene, D., \& Luft, P. (2002). Adoption of assistive technology for computer access among college students with disabilities. Disability \& Rehabilitation, 24, 1/2/3, 80-92.

Graves, L., Asunda, P. A., Plant, S. J., \& Good, C. (2011). Asynchronous online access as an accommodation on students with LD and/or ADHD in postsecondary STEM courses. Journal of Postsecondary Education and Disability, 24(4), 317-330.

Gkatzidou, V., \& Pearson, E. (2011). A community approach to the development of widgets to support personalised learning for disabled students. Paper presented at ASCILITE, 2011 'Changing Demands, Changing Directions, Hobart, Tasmania.

Hammer, S., Werth, S., \& Dunn, P. (2007). Tertiary students with a disability or chronic illness: Stigma and study in enabling pathways: 3rd National Conference of enabling educators, 25-27 Nov 2009, Toowoomba, Australia. Retrieved from eprints.usq.edu.au/6278/1/Hammer_Werth_Dunn_AV.pdf.

Hanafin, J., Shevlin, M., Kenny, M., \& McNeela, E. (2007). Including young people with disabilities: Assessment challenges in higher education. Higher Education, 54, 435-448.

Hanson, E., Magnusson, L., Arvidson, H., Claeson, A., Keedy, J., \& Nolan, M. (2007). Working together with persons with early stage dementia and their family members to design a user-friendly technology based support service. Dementia, 6(3), 411-434.

Hecker, L., Burns, L., Elkind, J., Elkind, K., \& Katz, L. (2002). Benefits of assistive reading software for students with attention disorders. Annals of Dyslexia, 52, 243-272.

Heiman, T., \& Olenik-Shemesh, D. (2012). Students with learning disabilities in higher education: Use and contribution of assistive technology, website courses and their correlation to students' hope and wellbeing. Journal of Learning Disabilities, 45, 308-318.

Heiman, T., Olenik-Shemesh, D., \& Kaspi-Tsahor, D. (2016). Effective use of ICTs in higher education: Students with and without disabilities perspective - obstacles and facilitators. Presented at the 15 th Canadian studies conference: Canada and Israel in a changing world: New trends and directions. Jerusalem, Israel.

Heiman, T., Coughlan, T., Rangin, H., \& Deimann, M. (2020). New designs or new Practice? Multiple perspectives on the ICT and accessibility conundrum. In Seale, J. (Ed). Improving accessible digital practices in higher education: challenges and new practices for inclusion. Palgrave Macmillan, Cham, Switzerland pp. 99-116.

HESA. (2019). HE student enrolments by HE provider and disability marker. Retrieved from: https://www. hesa.ac.uk/data-and-analysis/students/whos-in-he/characteristics

Iniesto, F., McAndrew, P., Minocha, S., \& Coughlan, T. (2016). Accessibility of MOOCs: Understanding the provider perspective. Journal of Interactive Media in Education, 2016(1).

Izzo, M. V., Murray, A., \& Novak, M. (2008). The faculty perspective on universal design for learning. Journal of Postsecondary Education \& Disability, 21(1), 60-72.

Jorgensen, M., Fichten, C. S., Nguyen, M. N., Budd, J., Barile, M., Asuncion, J., et al. (2015). Employment realities of recent junior/community college and university graduates and premature leavers with 
disabilities. International Journal of Disability, Community, and Rehabilitation, 14(1). Resource document. IJDCR. http://www.ijdcr.ca/VOL14_01/articles/jorgenson.shtml.

Kaspi-Tsahor, D. Heiman, T., \& Olenik-Shemesh, D. (2011). Assistive technology for students with blindness or visual impairments: Academic and social contributions. Presented at the 22nd Annual Conference of the Society for Information Technology \& Teacher Education International (SITE 2011). Nashville, Tennessee, USA.

Kimmons, R. (2017). Open to all? Nationwide evaluation of high-priority web accessibility considerations among higher education web-sites. Journal of Computing in Higher Education, 29, 434-450.

Knight, W., Wessel, R. D., \& Markle, L. (2018). Persistence to graduation for students with disabilities: Implications for performance-based outcomes. Journal of College Student Retention: Research, Theory \& Practice, 19(4), 362-380. https://doi.org/10.1177/1521025116632534.

Lazaar, J., Churchill, E. F., Grossman, T., Van de Veer, G., Palanque, P., Morris, J., \& Mankoff, J. (2017). Making the field of computing more inclusive. Communications of the ACM, 60(3), 50-59.

Lewthwaite, S. (2011). Disability 2.0: Student dis/Connections: A study of student experiences of disability and social networks on campus in higher education. $\mathrm{PhD}$ Thesis, University of Nottingham.

Ma, J., Pender, M., \& Welch, M. (2016). Education pays 2016: The benefits of higher education for individuals and society. Resource document. The College Board. https://trends.collegeboard. org/sites/default/files/education-pays-2016-full-report.pdf

Marien, M. (2002). Futures studies in the 21st century: A reality based view. Futures, 34(3), 261-281.

Maxwell, J.A \& Miller, B.A. (2008). Categorising and connecting strategies in qualitative data analysis. In P. Leavy, \& Hesse-Biber (Eds). Handbook of emergent methods. New York: Guildford press.

Martiniello, N., Barile, M., Budd, J., Nguyen, M.N., \& Fichten, C.S. (2012). Hotline: Students with disabilities speak out. Communiqué, 12(1), 14-15. Retrieved from https://www.cacuss. $\mathrm{ca} /$ content/documents/Link/Communique/Communique\%20November\%202011.pd

Mamiseishvili, K., \& Koch, L. C. (2012). Students with disabilities at 2-year institutions in the United States: Factors related to success. Community College Review, 40(4), 320-339.

McGuire, J. M., Scott, S. S., \& Shaw, S. F. (2003). Universal design for instruction: The paradigm, its principles, and products for enhancing instructional access. Journal of Postsecondary Education and Disability, 17(1), 10-20.

McNaught, A., MacMullen, R., Smith, S., \& Dobson, V. (2018). Evaluating e-book platforms: Lessons from the e-book accessibility audit. Learned Publishing, 31, 5-10. https://doi.org/10.1002/leap.1143.

Papadopoulos, G., Pearson, E., \& Green, S. (2011). An evaluation of accessibility simulations as a means of supporting inclusive practices in E-learning. In T. Bastiaens \& M. Ebner (Eds.), Proceedings of world conference on educational multimedia, hypermedia and telecommunications (pp. 3158-3167). Chesapeake, VA: AACE. Retrieved from http://www.editlib.org/p/38308.

Policy Connect. (2018). Accessible virtual learning environments: Making the most of the new regulations. Resource document. Policy Connect. https://www.policyconnect.org.uk/sites/site_pc/files/report/1134 /fieldreportdownload/appgatreport09-18final.pdf.

Price, G. (2006). Creative solutions to making the technology work: Three case studies of dyslexic writers in higher education. ALT-J-Research in Learning Technology, 14(1), 21-38.

Reed, M.J., Lewis, T., Lund-Lucas, E. (2006). Access to post-secondary education and services for students with learning disabilities: Student, alumni and parent perspectives from two Ontario universities. Higher Education Perspectives, 2, 2, Retrieved from http:/hep.oise.utoronto.ca/index.php/hep/article/view/617

Regadas, N., \& Ribeiro, A. (2011). Accessibility course: Training higher education academics in the University of Porto. In T. Bastiaens \& M. Ebner (Eds.), Proceedings of world conference on educational multimedia, hypermedia and telecommunications 2011 (pp. 2781-2787). Chesapeake: AACE Retrieved from http://www.editlib.org/p/38256.

Quirk, P. R., \& Conway, T. (2011). Accessibility and distance education. In T. Bastiaens \& M. Ebner (Eds.), Proceedings of world conference on educational multimedia, hypermedia and telecommunications 2011 (pp. 1594-1597). Chesapeake: AACE Retrieved from http://www.editlib.org/p/38074.

Roberts, J. B., Crittenden, \& Crittenden, J. C. (2011). Students with disabilities and online learning: A crossinstitutional study of perceived satisfaction with accessibility compliance and services. Internet \& Higher Education, 14, 242-250.

Roberts, K. D., \& Stodden, R. A. (2005). The use of voice recognition software as a compensatory strategy for postsecondary education students receiving services under of the category of learning disabled. Journal of Vocational Rehabilitation, 22, 49-64.

Roessler, R. T., \& Kirk, H. M. (1998). Improving technology-training services in postsecondary education: Perspectives of recent college graduates with disabilities. Journal of Postsecondary Education \& Disability, 13(3), 48-59. 
Roer-Strier, D. (2002). University students with learning disabilities advocating for change. Disability and Rehabilitation, 24, 17,914-17,924.

Rosenbaum, J. E. (2018). Disabilities and degrees: Identifying health impairments that predict lower chances of college enrolment and graduation in a nationally representative sample. Community College Review, 46(2), 145-175 https://doi.org/10.1177/0091552118762630.

Sanchez-Gordon, S., \& Luján-Mora, S. (2018). Research challenges in accessible MOOCs: A systematic literature review 2008-2016. Universal Access in the Information Society, 17(4), 775-789.

Scott, S. S., McGuire, J. M., \& Foley, T. E. (2003). Universal design for instruction: A framework for anticipating and responding to disability and other diverse learning needs in the college classroom. Equity and Excellence in Education, 36(1), 40-49.

Seale, J. (2020). New solutions, future possibilities. In J. Seale (Ed) Improving digital practices in higher education: Challenges and new practices for inclusion. Palgrave.

Seale, J. (2017). From the voice of a 'socratic gadfly': A call for more academic activism in the researching of disability in postsecondary education. European Journal of Special Needs Education, 32(1), 153-169.

Seale, J., Draffan, E. A., \& Wald, M. (2008). Exploring disabled learners' experiences of learning, LEXDIS Final Report to JISC. Available From: v1.lexdis.org.uk/project/media/LEXDIS_ProjectReport_Dec08 final.doc.

Seale, J., Georgeson, J., Mamas, C., \& Swain, J. (2015). Not the right kind of 'digital capital'? An examination of the complex relationship between disabled students, their technologies and higher education institutions. Computers \& Education, 82, 118-128.

Seale, J. K. (2014). E-learning and disability in higher education: Accessibility research and practice (2nd ed.). Abingdon: Routledge.

Seale, J. (2013). When digital capital is not enough: Reconsidering the digital lives of disabled university students. Learning, Media and Technology, 38(3), 256-269.

Seale, J., Draffan, E. A., \& Wald, M. (2010). Digital agility and digital decision-making: Conceptualising digital inclusion in the context of disabled learners in higher education. Studies in Higher Education, 35(4), 445-461.

Seale, J. (2006). E-learning and disability in higher education: Accessibility research and practice. Abingdon: Routledge.

Snyder, T. D., de Brey, C., \& Dillow, S. A. (2016). Digest of education statistics 2015 (51st Ed.) (NCES 2016-014). Resource document. National Center for Education Statistics, U.S. Department of Education... https://files.eric.ed.gov/fulltext/ED570993.pdf.

Stodden, R.A. \& Conway, M.A. (2003). Supporting individuals with disabilities in postsecondary education. American Rehabilitation, Autumn, 24-33.

The Open University Report (2018). Retrieved from: http://www.open.ac.il

Thompson, T., Burgstahler, S., \& Moore, E. (2007). Accessibility of higher education websites in the Northwestern U.S: current status and response to third party outreach. In Proceedings of the First International Conference on Technology-based Learning with Disability (pp127-136). Wright State University, Dayton, Ohio.

UCAS. (2018). Disabled students' allowances. Resource document. UCAS. https://www.ucas.com/studentfinance-england/disabled-students-allowances.

Unterfrauner, E., \& Weiermair-Märki, C. (2008). User requirements for adult learners with special needs in accessible lifelong learning. In Proceedings of the iLearning 2008 Forum. Retrieved from http://www. eife-1.org/publications/proceedings/ilf08/contributions/improving-quality-of-learning-withtechnologies/Unterfrauner_etal.pdf

Woodfine, B. P., Nunes, B. P., \& Wright, D. J. (2008). Text-based synchronous e-learning and dyslexia: Not necessarily the perfect match! Computers \& Education, 50, 703-717.

Publisher's note Springer Nature remains neutral with regard to jurisdictional claims in published maps and institutional affiliations. 